\title{
A SYSTEMATIC APPROACH TOWARDS RESTORATION OF HERITAGE BUILDINGS- A CASE STUDY
}

\author{
Sayali Sandbhor ${ }^{1}$, Rohan Botre ${ }^{2}$ \\ ${ }^{I}$ Assistant Professor, Dept. of civil engineering, Symbiosis Institute of Technology, Pune, India, \\ ${ }^{2}$ Graduate scholar, Dept. of civil engineering, Purdue University, USA, \\ sayali.sandbhor@sitpune.edu.in,botre.rohan@gmail.com
}

\begin{abstract}
Heritage structures perform vital role in nation's history, culture and signify the richness of it. To augment life and enhance strength, their restoration is very important for the future generations to have knowledge about how mankind lived in past ages. Restoration involves investigating, diagnosing and correcting deficiencies and deterioration of any structure. Identification of common defects and problems faced in old structures and devising a systematic approach towards handling these issues is civil engineer's obligation. A case study throws light on the various problems encountered and the methods employed to tackle them. This paper focuses on such problems and methodology to handle these problems while respecting structure's cultural integrity with the help of a case study. It also seeks to highlight the need for a greater awareness and the need to take precautionary measures of the immediate effects, and of the long-term management issues of heritage structures.
\end{abstract}

Index Terms: Heritage structures, defects, evaluation, systematic approach etc.

\section{INTRODUCTION}

Heritage buildings and monuments in any country are mute testaments of its glorious past [Meli et. al, 2007]. India has a very rich historic background which is evident from various buildings, forts, temples, landscapes, objects of historic era. Many of these were constructed several hundred years ago when the Indian Civilization was at its peak. Their architecture, design and construction at the time when computers, code of practice, design guidelines, research institutions and modern construction techniques did not exist makes one to realize the wisdom and expertise of our forefathers. These structures have managed to survive for hundreds of years while most of the modern constructions need repair after couple of years of service [Meli et. al, 2007]. Work is often performed to reverse decay or alterations made to the building after its initial construction. Physical materials of an earlier time, that might have been state of the art at the time of construction, might have failed and now need replacement with contemporary better functioning, but aesthetically similar materials. Such reasons make it mandatory to instigate a systematic approach in the area of heritage conservation.

\subsection{Restoration of heritage structure}

Building restoration refers to the process of correctly revealing the state of a historic building, as it looked in the past and recovering the same by various measures while respecting its heritage value. Restoration involves returning the existing fabric of a place to a known earlier state by removing accretions or by reassembling existing components without introducing new materials. Conservation means the process of retaining structure's historical, architectural, aesthetic, cultural significance. Preservation stands for maintaining the fabric of a place in its existing state and retarding deterioration whereas reconstruction implies returning a place as nearly as possible to a known earlier state and distinguished by the introduction of materials into the fabric. Restoration is defined as the act or process of accurately depicting the form, features, and character of a property as it appeared at a particular period of time by means of the removal of features from other periods in its history and reconstruction of missing features from the restoration period. [http://www.cr.nps.gov/hps/tps/standguide/restore/restore_ind ex.htm].

\subsection{Need of the study}

Most old cities have some monuments which represent the religious, military, political or economic powers of the past. The condition of such monuments is determined largely by their present function and use. Monuments which have no further utilization tend to decay rapidly, while monuments which are still in use have a better chance of being maintained [Steinberg F., 1996]. The extent of maintenance varies from structure to structure leading to deterioration of the structure. Restoration increases the total expected life of the structure by strengthening it to withstand all imposed loads. If the structure is not timely restored, its condition may worsen to an extent such that it becomes very difficult to regain its original condition. Restoration takes the structure to a new minimum 
strength level as seen from graph in Figure 1. It is necessary to follow a precise methodology, whose main steps are survey, diagnosis, safety evaluation, the choice of criteria and techniques of interventions, and finally the controls [Croci G.,2009].

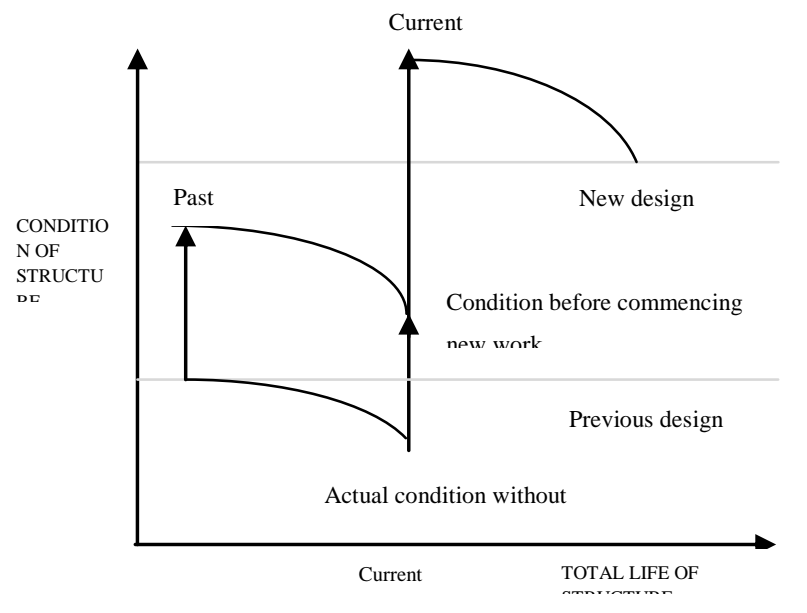

Fig -1: Need for restoration

\section{LITERATURE REVIEW}

The value of architectural heritage is not only in its appearance, but also in the integrity of all its components as a unique product of the specific building technology of its time [http://iscarsah.icomos.org/content/principles]. Verifying the structural reliability constitutes in itself a complex aspect of the problem which cannot be solved based solely on structural calculations. Complementary approaches involving historic research, comparative analyses and monitoring are also needed within the frame of a broader and more flexible understanding [Roca P.,2011]. The periodic monitoring of relevant parameters can help identify eventual deterioration phenomena. Thus, dynamic tests, in conjunction with model updating, are becoming reliable tools for non-destructively assessing historical structures [Rainieri C., 2011]. Lot of work has been done in the field of restoration in devising various innovative techniques of restoration. Every restoration work has its own challenges and ways to tackle them. These challenges may include visual appearance, architectural appearance, strength of the structure, present or proposed use of the structure etc. Research paper by Oudatzi K. [2010], attempts to use virtual 3D modelling in the field of restoration. As per the study of Thiru K.P.Mohandas, major problems any old structure face may be due to human negligence, human vandalism, overloading of roof, raised ground water level, wrong choice of materials, structural issues and climatic problems. 'Repair and strengthening guide for earthquake damaged buildings in Gujarat', gives measures for improvement of the seismic resistance of historic buildings. In the study by Cancellieri S. et al [2011], an integrated methodology concerning the diagnosis, based on non destructive testing (NDT) and techniques, is presented in order to better investigate materials and structures of historic importance. For the investigation of the ancient structure of Santa Maria in Gradi an integrated methodology has been used, combining traditional investigations and different types of NDT analysis, such as:

- Characterization of different period masonry materials, through maps of not homogeneous areas, i.e. areas with different type of bricks or stone blocks;

- Discovery of hidden structural elements, such as arches, columns, choirs included in the existing masonry;

- The description of the original construction techniques and typologies;

- Evaluation of structural performances through determination of damage in fractured masonries;

- The detection and classification of surface damage;

- Examination of structural vulnerability through investigation of physical/mechanical properties of mortars, stones and bricks;

- Inspection of previous refurbishment and/or maintenance techniques (injections, stitching armed joints).

L. Bertolini et al. [2011], infers that the conservation of RCC buildings of the cultural heritage is a challenge, since it requires the development of specific strategies aimed at finding the best compromise between the restoration of structural safety and the prevention of future damage and the preservation of the original materials and surfaces. Study of Yasser Korany [2011] states that the selected technique must be consistent with aesthetics, function, and the requirements of strength, ductility, and stiffness and provides an overview of the traditional and recent techniques proven to be effective in restoring heritage masonry structures. The special requirements for restoration of heritage structures and the main non-destructive evaluation methods that could be used to assess their structural condition are examined.

\section{SYSTEMATIC APPROACH}

Restoration and conservation is a fine balancing act, learning to judge just the right amount of intervention at the right time. Restoration of architectural heritage requires a multidisciplinary approach. It is known that heritage structures are meticulously designed and skilfully constructed structures. An equally competent and compatible strategy is required for their preservation. It should commence with an analysis to arrive at the structural system and the mechanism of load transfer [Kumar P., et.al, 2008].

As per Avrami E., et.al. [2000], in the cultural heritage conservation field, we are consistently faced with challenges on three fronts:

- Physical condition: Behaviour of materials and structural systems, deterioration causes and mechanisms, possible interventions, long-term efficacy of treatments, etc. 
- Management context: Availability and use of resources, including funds, trained personnel, and technology; political and legislative mandates and conditions; land use issues, etc.

- Cultural significance and social values: Why an object or place is meaningful, to whom, for whom it is conserved, the impact of interventions on how it is understood or perceived, etc.

All these challenges should be given due consideration to arrive at the best possible technique of restoration which will not only be effective but also economical. The proposed approach leads a restorer to efficient restoration practice by giving a logical sequence of various activities to be followed in restoration works. Identification of various problems and devising the most suitable method to tackle the same is the restorer's task. Choosing the most appropriate treatment, requires careful decision making about building's historical significance, physical condition existing on the date of restoration, proposed use and mandated code requirements etc [http://www.nps.gov/tps/standards/four-treatments/treatmentguidelines.pdf].

A general restoration approach shown in Figure 2 below may be adopted as a basis or guide for taking up work of restoration. According to the suggested systematic approach, restoration of heritage structure involves evaluation of structure to expose its actual condition. Evaluation is done based on documents and physical evidences by assessment of condition of structure which includes inspection, diagnosis and cause analysis. Evaluation may be exploratory or immediate. Immediate evaluation includes repairs of immediate nature which are desirable or necessary. Hence evaluation of the structural performance of buildings submitted to severe loading conditions is the most valuable source of knowledge regarding their weaknesses and the ways they respond to extreme conditions. These extreme conditions may be historic fire [Gomez Heras M., et.al, 2009], weathering of material, chemical reactions, water seepage, adverse weather conditions etc. Traces of their past performance can be retrieved by careful examination of its main elements or can be found in historic documents [Meli et.al, 2007]. On the basis of the evaluation report, quantum of deviation from original condition of the structure is known. It should then be treated by a suitable treatment which may include restoration, reproduction and reconstruction. The encountered problems need strategic planning so as to device suitable technique. Accordingly, a repair strategy can be devised. Repairs may be desirable or necessary. Method to be followed and the extent of changes to be made will depend upon the class of structure and limiting alterations that can be carried

out [http://www.urbanindia.nic.in/publicinfo/byelaws.htm].

Materials and features from the restoration period are identified, based on thorough historical research. Next, features from the restoration period are maintained, protected, repaired and replaced, if necessary. It also includes removal of features from other periods; missing features from the restoration period may be replaced, based on documentary and physical evidence, using traditional materials or compatible substitute materials. [http://www.cr.nps.gov/hps/tps/standguide/restore/restore_app roach.htm].

\subsection{Standards for Preservation, rehabilitation,}

\section{restoration and reconstruction}

Guidelines lead the stakeholders such as historic building owners and building managers, preservation consultants, architects, contractors, and project reviewers to develop the best suited approach prior to treatment The standards given by 'Archeology and historic preservation: secretary of the Interior's standards and guidelines, The National Park Service, U.S. are as follows [http://www.cr.nps.gov/locallaw/arch_stnds_8_2.htm]:

1. The historic character of a property should be retained and preserved. The replacement of intact or repairable historic materials or alteration of features, spaces, and spatial relationships that characterize a property should be avoided.

2. Each property should be recognized as a physical record of its time, place, and use. Work needed to stabilize, consolidate, and conserve existing historic materials and features should be physically and visually compatible, identifiable and properly documented for future research. Distinctive materials, features, finishes, and construction techniques or examples of craftsmanship that characterize a property should be preserved.

3. The existing condition of historic features should be evaluated to determine the appropriate level of intervention needed. Treatments that cause damage to historic materials should not be used.

4. Deteriorated historic features should be repaired rather than replaced. Where the severity of deterioration requires replacement of a distinctive feature, the new feature should match the old in design, colour, texture, and, where possible, materials. Replacement of missing features should be substantiated by documentary and physical evidence.

5. New additions and adjacent or related new construction will be undertaken in such a manner that, if removed in the future, the essential form and integrity of the historic property and its environment would be unimpaired.

6. Replacement of missing features from the restoration period should be substantiated by documentary and physical evidence. A false sense of history should not be created by adding conjectural features, features from other properties, or by combining features that never existed together historically. 
7. Reconstruction should be used to depict vanished or nonsurviving portions of a property when documentary and physical evidence is available to permit accurate reconstruction with minimal conjecture and should be based on the accurate duplication of historic features and elements. A reconstructed property should re-create the appearance of the non-surviving historic property in materials, design, colour, and texture.

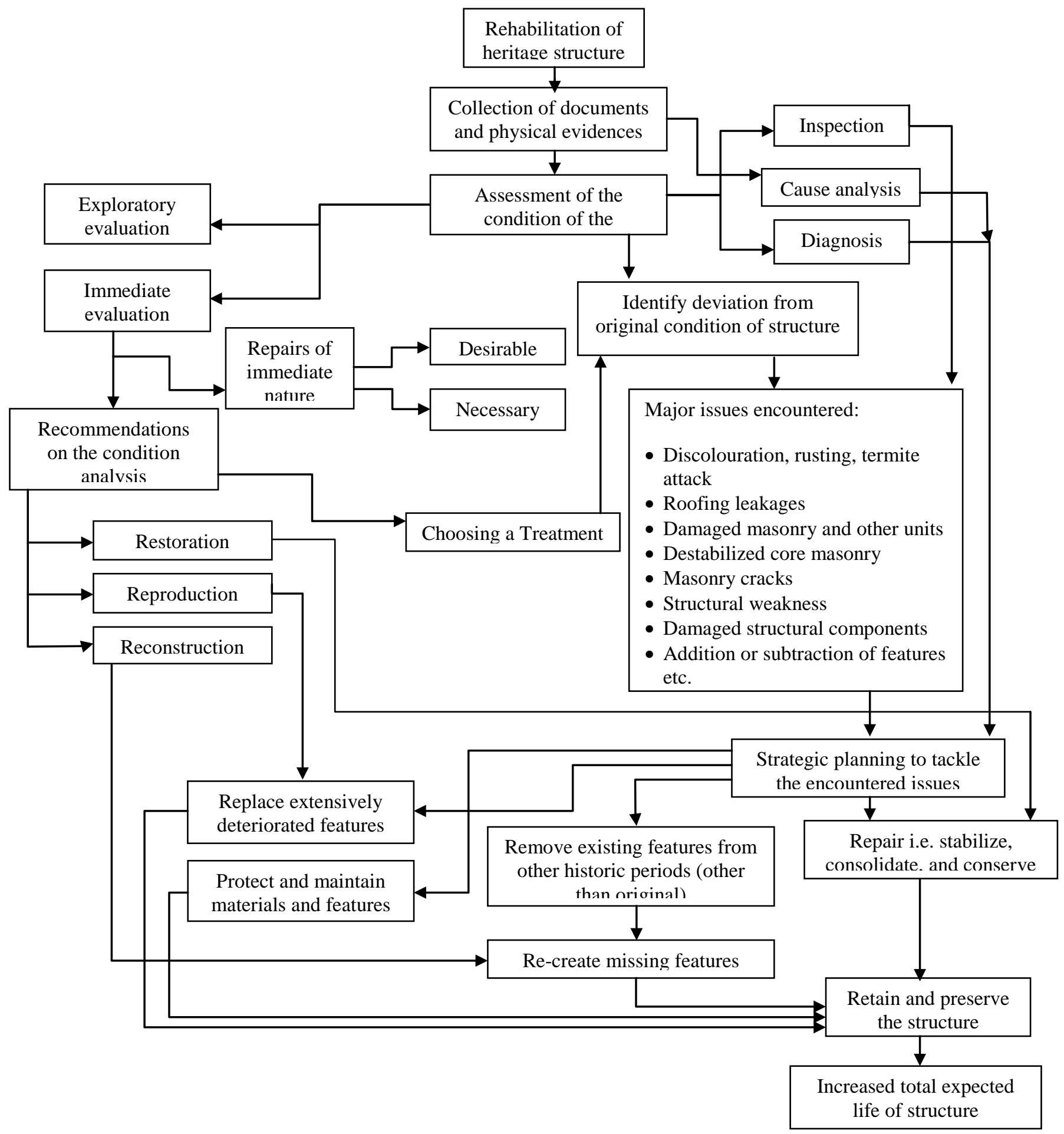

Fig- 2: Systematic approach 
Hence effort of restoration should bring back the building to its original form and beauty without necessarily sacrificing authenticity. The monument must therefore be analysed and appreciated to enable the recapturing of the original fabric and character of the heritage structure through judicious investigation \& scientific methodology and it must be complemented and enhanced with the minimum of intervention and at a reasonable cost [Rene Luis S. Mata,2009]. A case study of restoration work throws light on the various aspects involved and the respective techniques implemented.

\section{CASE STUDY}

To study the way in which typical rehabilitation work in India is carried out, study of rehabilitation of main building, University of Pune has been carried out. The building is indexed as a Grade I structure [http://www.urbanindia.nic.in/publicinfo/byelaws.htm], which was constructed in 1871 by the British. Designed by the then architect James Trubshawe, the building is a G+1 structure with 60,000 sqft area having shallow foundation resting on black cotton soil. The typical features include sloping pitch roof, jack arch slab, typical wooden flooring, un coursed rubble masonry in an Italian gothic architecture.

The project entailed the restoration and rehabilitation of the historic University main building. Useful life of a structure being considered as 100 years, it was of utmost importance to rehabilitate the structure to the earliest. Assessment of structure involved rapid visual screening, data collection, condition assessment. The visual inspection brought to notice many defects and proper investigation including non destructive testing of various components revealed the actual condition and hence validated the urge to take up work of restoration of this historic precinct.

\subsection{Major Problems and remedial measures}

Buildings may show some degree of movement depending on factors such as shrinkage, temperature gradients, the degree of restraint from foundations, geometry etc., as well as loading conditions from wind and snow. Deterioration caused by such factors and its treatment is examined on site for the case study. Poor design and construction defects can create poor load distribution that can result in undesirable concentrations of stresses. Major problems encountered in the assessment of structure and the corresponding plan of action is as stated below.

\subsubsection{Structural cracks in masonry walls \& damaged masonry with loose bonding}

Poor load distribution, poor water proofing causing bulging of structural members had caused the members to crack with cracks of varying magnitudes. The cracks observed on site were not only superficial but also extended to the core of the masonry. The entire north side of the structure along with northwest and northeast corners was covered with very thick creepers. The roots had penetrated in the wall through the joints in masonry. Thus the gaps in the joints had increased (Figure 3). The creepers had pulled out the upper portion of the corner. Hence the upper portion of the wall was leaning out of plumb. Masonry damage was the result of aging of the structure and materials, poor water proofing, wrong loading conditions etc. The destabilization of older walls due to the deterioration of the inner core rubble between the exterior and interior faces of masonry needed proper attention. 1

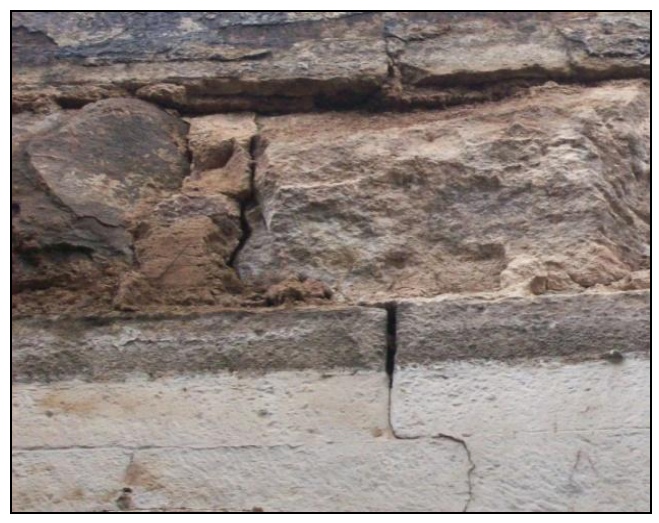

Fig -3: increased gap in joints due to growth of creepers

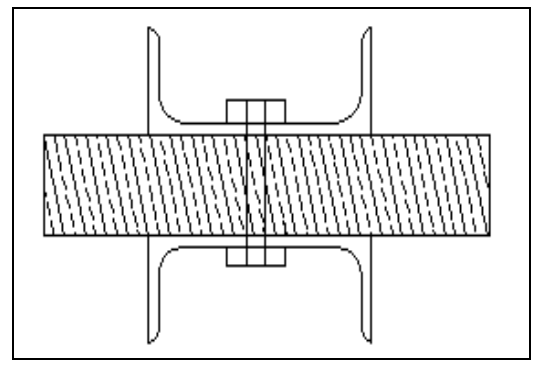

Fig -4: Reinforcement details of the wall face

\section{Remedial measures}

Epoxy grouting for strengthening weakened and cracked masonry, jacketing of disturbed wall surfaces by means of applying a mesh of non-ferrous steel reinforcement to both sides of the wall, bonded to the wall with a mortar matrix, metal straps with bolted connections are some of the measures to repair \& avoid any further cracking of masonry. The gaps in the joints of the masonry can be filled up with lime mortar. Also stitching can be done to avoid further damage. In the case study, the repair of masonry cracks was taken care by filling all the cracks by epoxy grout with the help of inserted nipples and grouting gun. After the grouting was completed, plinth beam was casted and steel $\mathrm{C}$ sections were placed on both the sides of the wall bolted with each other through the wall cross section as shown in Figure 4. A mesh of $8 \mathrm{~mm}$ 
reinforcement bars was placed on the wall as shown in Figure 6 and then the face was shotcreted with suitable mix of concrete and plastered with the conventional material mix lime mortar 1:3. Details of the reinforcement of damaged masonry walls are given in Figure 5.

Dealing with heavily damaged masonry included removal of defective stonework from areas showing loose bonding, structural faults, cracks and major shifts in plumbs or alignments, procurement of matching stones from quarries to match in strength, mineral composition, colour and appearance, analysis of mortar used in the masonry to reveal ingredients and their proportions to obtain specifications for rebuilding masonry, dressing of broken stones in prescribed shapes and sizes and fixing them in position using the mortar derived from above analysis followed by dressing stones in place.

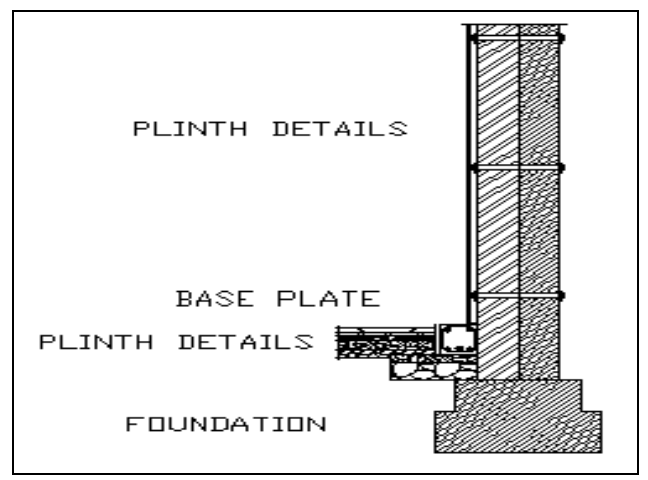

Fig -5: Details of plinth and reinforcement

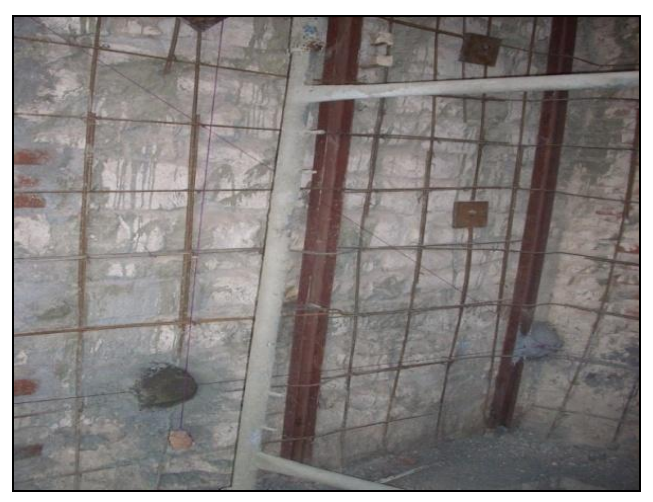

Fig -6: C/s of wall and plinth details

\subsubsection{Crack in the Masonry and lime concrete slab}

Thick creepers were allowed to grow on the masonry. The creepers had its only support from the wall thus causing the roots to grow in the masonry joints. The slab consisted of steel sections supporting lime concrete. Ceiling tiles in terracotta were laid below the lime concrete and were visible from below. The Rolled Steel Joists (450 $\mathrm{mm}$ deep) did not have any binding or bracing at the outer face of the porch to prevent it from moving outwards. This allowed the upper portion of the wall to be pulled out by the heavy creepers. The absence of fixity either using nut-bolts or welding had further allowed the walls of the porch to lean out of plumb by 25-30 mm. After opening up the waterproofing on the slab, 20-25 $\mathrm{mm}$ wide cracks were observed in the lime concrete slab towards southern side running in east-west direction. It was also observed that the T-sections at the outer face had corroded due to the water seepage in presence of lime concrete, considerably reducing the cross-section area of the steel members (Figure 7). This had made the slab structurally instable that could have collapsed without any warning.

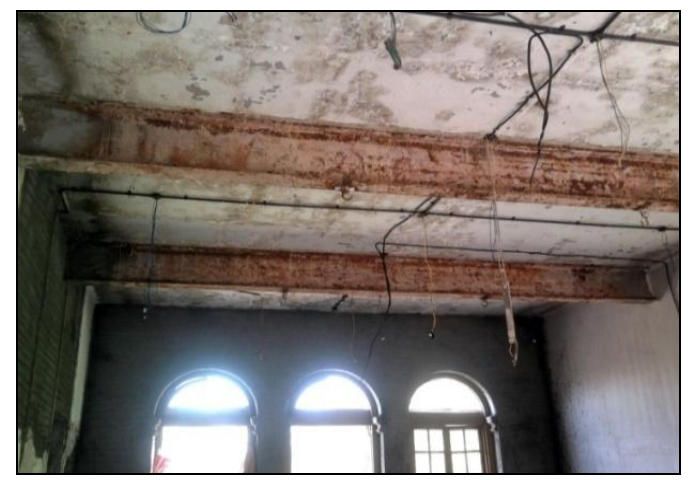

Fig -7: Corroded steel members due to leakage

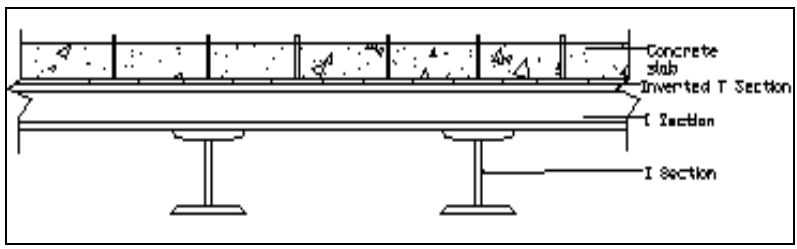

Fig -8: Details of reconstructed porch slab

\section{Remedial Measures}

Part of the porch was dismantled and the wall was reconstructed in plumb. Damaged stones were replaced. Steel members were fixed by welding and damaged steel sections were replaced. Also bracing at the joist level was added. Old slab was replaced with similar slab structure as shown in Figure 8 which consisted of stack of two I sections one above the other supporting inverted T section. Concreting of suitable grade was done over the inverted T-section. Proper care was taken to provide brick bat coba type of water proofing so as to reduce future deterioration.

\subsubsection{Collapse of portion of column}

The column which was supporting overhead beams showing major signs of bulging due to water seepage collapsed partially which initiated the urgency to rehabilitate the structure. The intact portion of the column showed loose bonding of the mortar as well as cracks in the core which needed special attention (Figure 9). 


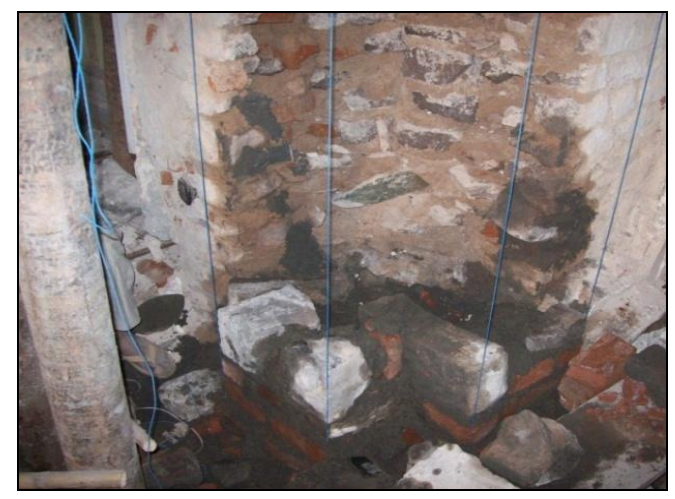

Fig -9: Reconstruction of partially collapsed column

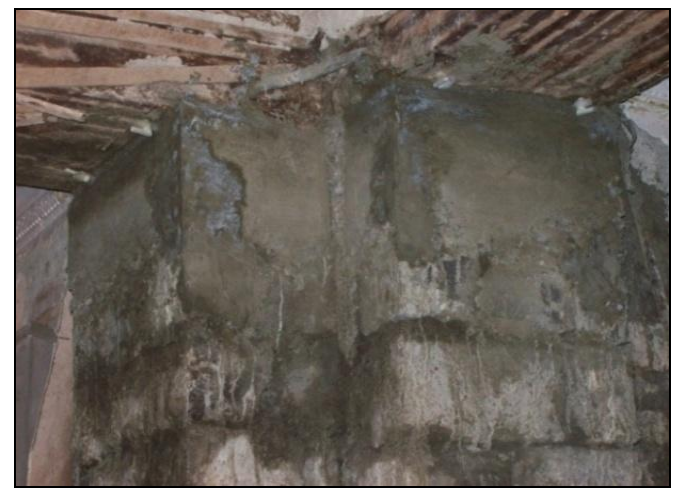

Fig -10: Grouting nipples at the top to fill voids

\section{Remedial Measures}

The collapsed portion was removed and reconstruction of that portion was carried out using the same type of stone and mortar. During the reconstruction, steel rods were inserted into the old masonry so as to establish a proper bond between the old and the new masonry. After the reconstruction, the cracks in the core of the column were taken care by the epoxy grouting carried out through the inserted nipples (Figure 10).

\subsubsection{Bulging wall \& Major longitudinal crack in}

\section{beam}

The internal wall on eastern side was found showing signs of bulging. The rainwater gutter on the terrace, which is above this wall, was sagged due to water seepage observed in the first floor wall as seen from Figure 11. The wall was bulged at this location on first floor and also some cracks had appeared in the plaster of the wall on ground floor at same location.

Remedial measures

The reason for the bulging of this wall was found to be a corroded gutter above the wall, which allowed the water to seep in the wall thus the gutter needed to be replaced and laid with proper slopes. The bulge in the wall also needed to be checked for its stability and also it was necessary to ensure if the cracks in the wall could be rectified by stitching or the required part of the wall could be dismantled and replaced with minimal disturbance to the rest of the structure to ensure proper transfer of loads through the walls.

Bulged wall resting above the beam caused the beam to have sag at the centre leading to a structural crack. This major longitudinal crack posed a major problem and required flitching of the beam with steel plates on the exposed sides after the wall resting on it is removed. The steel plates were then bolted to the beam by anchor and through bolts as shown in Figure 12. After restoring the beam, the wall above was reconstructed.

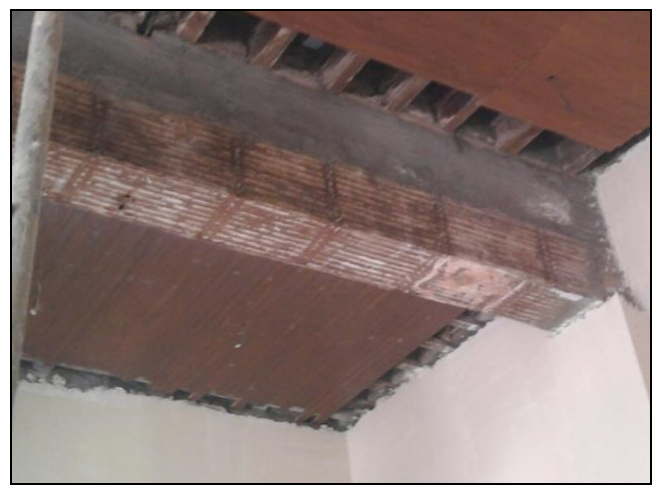

Fig -11: Longitudinally cracked beam with visible sag

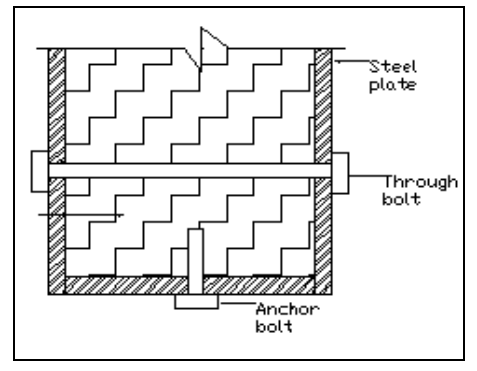

Fig -12: Flitching details of beam

\subsubsection{Roofing leakages}

The roof is constructed in lime concrete slab using chickenmesh. This slab is covered with mangalore tiles laid above corrugated G.I. sheets (Figure 13). The mangalore tile roofing did not have a proper slope for storm water drainage. Thus water logging at the corners was observed which allowed growth of trees. Seepage through roofs and down-take pipes had resulted in the bulging of stone masonry and severe cracking of the brick masonry below on the ground floor. There were several places where the storm water from roof did not reach the ground and seeped in the structure due to improper laying of storm water drains or inadequate maintenance. 


\section{Remedial measures}

The repair technique comprised of restoring proper slopes, replacing corroded members, using lead flashing wherever necessary. The down take pipes that travel through inaccessible panelling through the centre of the building were taken through more accessible positions with strict schedules of periodic maintenance. The bulged and cracked masonry was taken care of as per the requirements. State of the art devices for detection and alarm in case of fire were installed in the roof voids and other infrequently accessed spaces of the building. Several changes in the profiles of roofs were done to ensure better performance of roofs. The repaired roof was then covered with panels coated by multiplas sheets for water proofing (Figure 14).

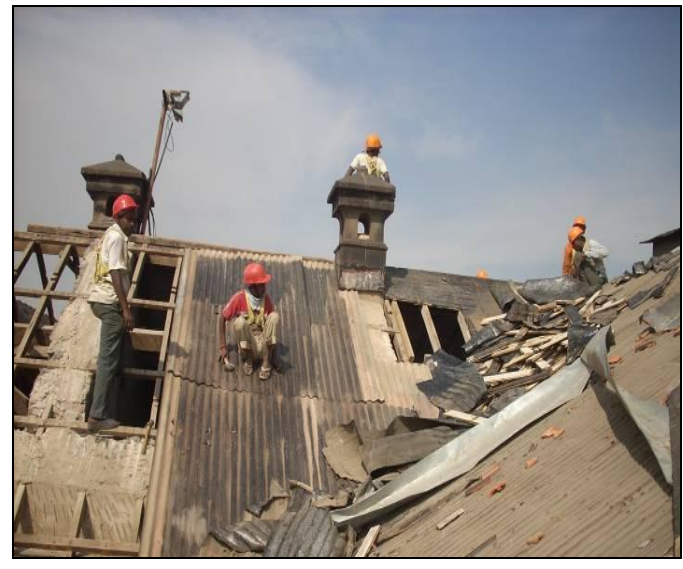

Fig -13: Dismantling of deteriorated roof members

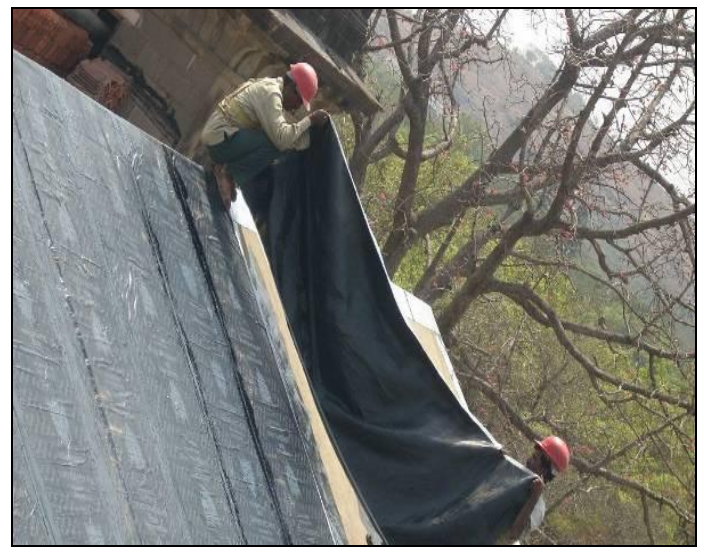

Fig -14: Laying of Multiplas sheet for waterproofing

\section{FINDINGS \& DISCUSSION}

As the selected project for case study is of complicated nature with hidden difficulties, the exact time estimate for completion of restoration cannot be prepared. The construction work is costlier than any other conventional construction project because of the techniques and the difficulties involved in it. Material procurement is a major problem posed because of their specifications, colour, texture, quality, strength aspects, use of the original material should be encouraged as far as possible. Heavily deteriorated material may be replaced by new material of same quality.

Rapid visual screening involves visual inspection and analysis of structure based on past experience. Data collection involves building description, various detailed drawings, reconnaissance survey, preliminary survey, map preparation, geotechnical report, construction specifications available, exposure condition, geological report, variable for analysis, condition assessment, initial inspection \& appraisal, review of document, detailed investigation, reporting and recommendation. Detailed investigation is the most important step in restoration works of heritage structures.

In the case study, the NDT reports depicted that the masonry core strength was reducing and hence required either strengthening or replacement. Hence decision of wall strengthening is appropriate as replacement would be costlier. Flitching of beam strengthens the beam as well as takes care of the longitudinal crack and at the same time avoids disturbing the whole structure for beam replacement. Partial column replacement saves in material and hence proves economical. Insertion of reinforcement ensures proper bond between old and new masonry. Casting of slab using concrete could have been done with precast concrete members thus saving time of construction. After the complete restoration of the structure it is recommended to practice regular maintenance to ensure its proper working in future and increased minimum strength level.

\section{CONCLUSIONS}

Deterioration of the structure may be caused due to various reasons, some of which are long life, lack of maintenance, unchecked growth of trees \& creepers on the structures, improper drainage system, irregular inspection, material deterioration and weathering effect etc. Also, modern codes and building standards, observance of cultural context, conservation criteria, attainable benefit, traditional and innovative methods etc. pose major challenges in restoration of heritage structure. The best therapy to reduce decay is preventive maintenance. Adequate maintenance can limit or postpone the need for subsequent intervention. The repair process requires the existing condition of the structure to be identified and its causes of its deterioration. It is also necessary to define how ongoing deteriorative factors should be monitored given the effects of such processes on the rehabilitation of the structure [Ghadban S.S.,2011]. An understanding of the significance of the structure should be the basis for conservation and reinforcement measures. The design of intervention should be based on a clear understanding of the kinds of actions that were the cause of the damage and decay as well as those that are taken into account for the analysis of the structure after intervention; because the design will be dependent upon them. The choice 
between "traditional" and "innovative" techniques should be weighed up on a case-by-case basis and preference given to those that are least invasive and most compatible with heritage values, bearing in mind safety and durability requirements. The removal or alteration of any historic material or distinctive architectural features should be avoided whenever possible. Deteriorated structures whenever possible should be repaired rather than replaced [ICOMOS charter].

Historic structures pass on a message coming through the ages. It is the responsibility of the present generation to carry it forward to the future generations [http://www.windfallcentre.ca/index. php?st=1\&s=Heritage Retrofits\& $p=$ Overview].This gift may be lost if the integrity of the original structure is destroyed to meet the present demands. As these structures are closely related to local social and economic conditions, methods which may be less destructive and of original fabric need to be devised to approach these issues. There is tremendous educational and practical potential to be realized in the area of restoration. An architectural, engineering, management as well as social approach is required for such type of endeavour. Proper education and training for such kind of works is today's need. Involvement of more practitioners and technical professionals is required. The potential of this field needs to be realized by integrating and contextualizing the spheres and work of conservation, not only as a self-contained science or technological endeavour but also as a social practice.

\section{REFERENCES}

[1] Chapter-8, Conservation of heritage sites including heritage buildings, heritage precincts and natural feature areas, Model Building Bye-laws, http://www.urbanindia.nic.in/publicinfo/byelaws.htm,

Retrieved August 2012

[2] Sanghamitra Basu, Preservation of heritage structures $\&$ earthquake issues, guidelines and lessons from the past, Chapter 27, 'Repair and strengthening guide for earthquake damaged buildings in Gujarat' NPCBEERM, MHA (DM), Govt. of India.

[3] Prabhat Kumar, Ashish K. Singh (2008), Preservation of heritage buildings and monuments, NBMCW February 2008.

[4] Meli, Roberto and Sánchez-Ramírez, Roberto(2007) 'Criteria and experiences on structural rehabilitation of stone masonry buildings in mexico city', International Journal of Architectural Heritage, 1: 1, pp 3 -28.

[5] Florian Steinberg (1996), Conservation and rehabilitation of urban heritage in developing countries, Habitat Intl. Vol. 20, No. 3, pp. 463-475, 1996.

[6] Ghadban S.S., Ashhab M. (2011), Stone restoration practice in palestinian territories: a case study from jerusalem, Journal of Architectural Conservation, Volume 17, Issue 3, November 2011

[7] Miguel Gomez-Heras, Stephen McCabe, Bernard J. Smith, Rafael Fort (2009), Impacts of fire on stone built heritage, an overview, Journal of Architectural Conservation, Volume 15, Issue 2, July 2009

[8] Croci G. (2000), General methodology for the structural restoration of historic buildings: the cases of the Tower of Pisa and the Basilica of Assisi, Journal of Cultural Heritage, Volume 1, Issue 1, January 2000, Pages 7-18.

[9] Avrami E., Mason R., Martade la Torre (2000), Values and Heritage Conservation, Research Report, The Getty Conservation Institute, Los Angeles

[10] Icomos charter- principles for the analysis, conservation and structural restoration of architectural heritage (2003),

http://iscarsah.icomos.org/content/principles/ISCARSA H_Principles_English.pdf

[11] Pere Roca (2011), Restoration of historic buildings: conservation principles and structural assessment ,International Journal of Materials and Structural Integrity 2011, vol.5, no.2-3, pp. 151-67. ISSN: 17450055 (print), Publisher: Inderscience Enterprises Ltd. Country of Publication: UK

[12] Rainieri, Carlo; Fabbrocino, Giovanni. Geofizika. (2011), Operational modal analysis for the characterization of heritage structures., Vol. 28 Issue 1, p109-126.

[13] Thiru K.P.Mohandas, Strengthening and Restoration of Heritage Buildings, Session II, Archaeological survey of India, Chennai Circle, Chennai, Accessed at : http://www.cmdachennai.gov.in/pdfs/seminar_heritage _buildings/Strengthening_and_Restoration_of_Heritage _Buildings.pdf

[14] Oudatzi, K.(2010), Virtual reality in restoration of historic buildings: $3 \mathrm{~d}$ model projection of the restoration project of Alaca Imaret Câmi with intuitive and interactive application through hyper realism technology, Virtual Systems and Multimedia (VSMM), 2010 16th International Conference on 20-23 Oct. 2010, pp $361-364$.

[15] Stefania cancellieri, Massimo poggi (2011), Innovation technology and sustainable design as methodological path to the preservation of cultural heritage, Accessed at: www.ndt.net/article/art2011/papers/POGGI\%20\%20NDT\%2042.pdf

[16] L. Bertolini, M. Carsana, M. Gastaldi, F. Lollini, E. Redaelli (2011), Corrosion assessment and restoration strategies of reinforced concrete buildings of the cultural heritage, Materials and Corrosion, Volume 62, Issue 2, pages 146-154, February 2011.

[17] Yasser Korany (2011), Effective techniques for restoration of heritage masonry, International Journal of Materials and Structural Integrity (IJMSI), Vol. 5, No. 2/3, 2011.

[18] Rene Luis S. Mata (2009), Heritage Conservation: Applying Scientific Method in Architecture The Lingayen Capitol Building (1918), MUHON: A Journal of Architecture, Landscape Architecture and the Designed Envi ronment, is su e n o. 3, pp 28-37. 
[19] http://www.cr.nps.gov/hps/tps/standguide/restore/restor e_index.htm, Retrieved August 2012.

[20] http://www.cr.nps.gov/hps/tps/standguide/restore/restor e_approach.htm, Retrieved August 2012.

[21] http://www.cr.nps.gov/local-law/arch_stnds_8_2.htm, Retrieved August 2012.

[22] http://www.nps.gov/tps/standards/fourtreatments/treatment-guidelines.pdf, Retrieved January 2013.

[23] http://www.windfallcentre.ca/index.php?st=1\&s=Herita ge_Retrofits\&p=Overview, Retrieved September 2012.

\section{BIOGRAPHIES}

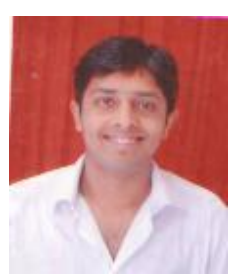

Rohan Botre, Graduate scholar, Dept. of civil engineering, Purdue University, USA, botre.rohan@gmail.com

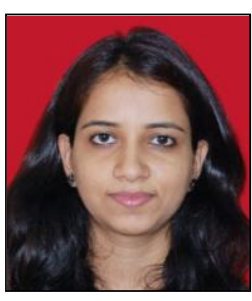

Sayali Sandbhor, Assistant Professor, Dept. of civil engineering, Symbiosis Institute of Technology, Pune, India, sayali.sandbhor@sitpune.edu.in 